\title{
The Impact of Thiamine Treatment on Generalized Anxiety Disorder
}

\author{
Khanh vinh quốc Lương, Lan Thi Hoàng Nguyễn \\ Vietnamese American Medical Research Foundation, Westminster, USA. \\ Email: Lng2687765@aol.com \\ Received May $16^{\text {th }}, 2011$; revised July $15^{\text {th }}, 2011$; accepted August $20^{\text {th }}, 2011$.
}

\begin{abstract}
Objective: Patients with generalized anxiety disorder (GAD) are fearful. They constantly worried about minor matters, and they anticipate the worst. The GAD is diagnosed when a patient experiences excessive anxiety and worry for at least 6 months. The cause of GAD is unknown. In the present paper, we discuss patients with GAD who have low levels of thiamine in their bloods. We also discuss the role of thiamine in the pathogenesis and treatment of GAD. Methods: We examined 9 patients (6 males and 3 females) who met the DSM-IV-TR diagnostic criteria for GAD. These patients had no history of alcoholism. Their ages ranged from 57 to 83 years old (mean age $-72.8 \pm 2.9$ years). All of the patients had low blood thiamine levels (mean $-25.1 \mathrm{nmol} / \mathrm{L} \pm 6.0 \mathrm{nmol} / \mathrm{L} ;$ normal level $-70 \mathrm{nmol} / \mathrm{L}-180 \mathrm{nmol} / \mathrm{L}$ ). Participants completed the Hamilton Anxiety Rating Scale (HARS) for anxiety before and after thiamine treatments. All of the patients received daily thiamine $100 \mathrm{mg}$ intramuscularly. Results: Thiamine supplementation significantly improved HARS scores, increased both appetite and general well-being, and reduced fatigue in patients with GAD. Interestingly, these patients were able to discontinue taking anxiolytic and $\beta$-blocker medications. Conclusion: Parental thiamine significantly affects patients with GAD.
\end{abstract}

Keywords: Thiamine, General Anxiety Disorder, Vitamin $B_{1}$, Anxiety

\section{Introduction}

Patients with generalized anxiety disorder (GAD) are fearful, they constantly worry about minor matters, and they anticipate the worst. A diagnosis of GAD is made when a patient experiences excessive anxiety and worry for at least 6 months, involving multiple events or activities. However, the National Comorbidity Survey Replication database has indicated that many people have GAD-like symptoms for less than 6 months. Kessler et al. [1] suggested that the reasons for not diagnosing people with GAD might need to be re-evaluated. An epidemiological study reported that patients with GAD exhibit high degrees of comorbidity with major depression $(59 \%)$ and other anxiety disorders $(56 \%)$ [2]. GAD is the most disabling and costly anxiety disorder seen in primary care $[3,4]$. Moreover, only $18 \%$ of patients with GAD who were followed over a 5-year period achieved full remission $[5,6]$. The cause of GAD is unknown. There are many biological theories concerning the etiology of GAD, such as the following: alterations in the structure and function of the amygdale [7], abnormalities of the $\gamma$ aminobutyric acid (GABA)-benzodiazepine receptor [8], noradrenergic activation [9], serotonergic deregulation [10], and modest genetic component [11]. Benzodiazepines are commonly used as a first-line GAD treatment. However, newer medications such as buspirone, serotonin and norepinephrine reuptake inhibitors (SNRIs) have begun replacing benzodiazepines in the treatment of GAD. Some patients may become dependent on benzodiazepines. In the meantime, the prevalence of mental health disorders has increased in developed countries in correlation with the Western diet [12]. Some investigators have reported that nutritional deficiencies are associated with some mental disorders [13]. Thiamine deficiency, common to alcoholism, can produce confusion and psychotic symptoms, in addition to neurological deficits. Low plasma thiamine levels have also been observed in cognitively impaired elderly patients [14].

Therefore, we examined patients with GAD who presented low levels of blood thiamine. This paper also discusses the role of thiamine in the pathogenesis and treatment of GAD.

\section{Methods and Results}

We examined 9 patients (6 males and 3 females) who met 
the DSM-IV-TR diagnostic criteria for GAD. Their ages ranged from 57 to 83 years old (mean- $72.8 \pm 2.9$ years). All of the patients had low blood thiamine levels (mean, $25.06 \mathrm{nmol} / \mathrm{L} \pm 6.0 \mathrm{nmol} / \mathrm{L}$; normal level $-70 \mathrm{nmol} / \mathrm{L}$ $180 \mathrm{nmol} / \mathrm{L}$ ). These patients had no history of alcoholism; however, they did present histories of hypertension, type 2 diabetes or both. Patients completed the Hamilton Anxiety Rating Scale (HARS) before and one week after thiamine treatment (the mean HARS scores were 27.33 and 5.8, respectively).The HARS has been used in numerous GAD treatment studies [15]. All of the patients received daily thiamine $100 \mathrm{mg}$ intramuscularly for 2 - 4 weeks.

Thiamine supplementation improved HARS scores, increased appetite and general well-being, and decreased fatigue in patients with GAD. Interestingly, these patients were able to discontinue the use of anxiolytic and $\beta$ blocker medications.

\section{Discussion}

In the present study, all of the patients presented low blood thiamine levels. Thiamine is important to glucose energy-utilization pathways, particularly in the central nervous system, which needs a continuous supply of glucose. Thiamine deficiency is characterized by a selective loss of neurons in the hypothalamus, midbrain, brainstem and cerebellum of humans and animals $[16,17]$. Encephalopathy due to thiamine deficiency may involve impairment of the function of cholinergic neurotransmitters. Thiamine is a coenzyme that is required for the synthesis of acetylcholine (ACh). The synthesis of ACh is impaired in the brains of thiamine deficient rats [18], which leads to a significant reduction of neural ACh levels [19]. Using biochemical analyses, Mair et al. [20] demonstrated that the concentration of norepinephrine was significantly reduced in the brain of rats' (at both the cortex-hippocampus boundary and in the olfactory bulbs). Furthermore, this reduction in norepinephrine was accompanied by a concomitant decrease in learning and memory in the thiamine-deficient rats. Animal studies have suggested that thiamine is involved in the presynaptic release of ACh. Thiamine binds to nicotinic receptors and may exhibit anticholinesterase activity [21]. Moreover, thiamine deficiency induces an early central muscarinic cholinergic lesion [22]. The muscarinic cholinergic synaptic receptor densities were reduced by $30 \%$ in the homogenates of the hippocampus and by $40 \%$ in the homogenates of the temporal cortex of alcoholics [23,24]. Patients with GAD had fewer $\alpha_{2}$-adrenergic receptors than did control subjects [25]. A blunted growth hormone response to clonidine in patients with GAD indicated that these patients exhibit decreased postsynaptic $\alpha_{2}$-adrenergic receptor sensitivity [26].
Dicethiamine hydrochloride, an analogue of thiamine, improved performance in an animal model of complex fatigue [27]. Sulbutiamine, a highly lipophilic thiamine derivative, is an antiasthenic compound that can cross the blood brain barrier and selectively active on specific brain structures that are directly involved in asthenia [28]. Kreisler et al. [29] observed the effects of an induced vitamin B complex deficiency that caused severe primary mental changes or aggravations of pre-existing symptoms in psychotic patients. In a retrospective study, Mishra et al. [30] investigated the relationship between vitamin B intake in childhood and subsequent psychological distress in adulthood. They found that adult women who consumed less thiamine during childhood experienced more psychological distress; however, this relationship disappeared when the authors adjusted for smoking confound. In another study, a psychotic patient responded to intramuscular administration of thiamine $100 \mathrm{mg}$ [31]. Gontzea et al. [32] assessed the thiamine status of patients with neurosis in a psychiatric department. They observed decreases in thiamine excretion and erythrocyte transketolase activity in patients with neurosis compared to healthy control participants, suggesting that the psychiatric patients had thiamine deficiencies. In a controlled trial, Benton et al. [33] demonstrated a significant association between improved thiamine status and enhanced performance across a range of cognitive function tests in women. They observed significant cognitive deteriorations when the subjects were deprived of thiamine using the psychoneurotic scales of the Minnesota Multiphasic Personality Inventory (MMPI); however, thiamine supplementation reversed these effects [34]. Smidt et al. [35] found that healthy elderly Irish women responded to thiamine supplementation with significantly increased appetites, energy intakes, and general wellbeing as well as decreased fatigue. Heseker et al. [36] noted that low levels of thiamine, ascorbic acid and folate associated with poor mood. Thiamine and other B vitamins augmented tricyclicanti depressants in the treatment of affective and cognitive disturbances in geriatric depression [37].Thiamine supplementation improved the symptoms of neurotic patients [38]. Wilkinson et al. [39] noted that thiamine supplementation improved the quality of life of subjects with persistently low thiamine pyrophosphate levels. Students who took extra thiamine had more than doubled their scores on the clear-headedness and mood subscales of the Profile of Mood States (POMS) psychological test [40].

The intestinal absorption of thiamine is normally sufficient in young people but may decrease with age [41]. Schaller and Holler [42] reported that intestinal ALP is involved in the active thiamine absorption in the intestinal tract. Furthermore, Rindi et al. [43] found that intes- 
tinal ALP can transphosphorylate thiamine to thiamine monophosphate during intestinal transport in rats. Without ALP, thiamine cannot be transported into the lumen of the gastrointestinal tract [44]. The decrease in intestinal ALP activity that is observed in older rats has been attributed to the reduction of enterocytes caused by the age-induced atrophy of intestinal mucosa [45]. The enzymatic activity of ALP in the duodenum was also found to be significantly higher in 5-month-old rats compared to the other age groups; this differences stark between the 2.5-week-olds and 23-month-olds [46]. The decrease in intestinal ALP activity of older rats has been attributed to the reduction of the number of enterocytes caused by the age-induced atrophy of intestinal mucosa [45].

In humans, single oral doses of thiamine above $2.5 \mathrm{mg}$ are mostly unabsorbed [47,48]. Baker et al. [49] demonstrated that only the intramuscular administration of thiamine was able to correct thiamine deficiencies in subjects over 60 years-old. Sasaki et al. [50] reported a case study of a patient with a thiamine deficiency and psychotic symptoms. Only repeated intravenous administration thiamine ameliorated the condition of patients. In addition, patients responded rapidly to large doses of parental thiamine during the early stages of thiaminedeficient encephalopathy (i.e., Wernicke's encephalopathy). The initial dose of thiamine is usually $100 \mathrm{mg}$ two to three times daily for 1 to 2 weeks.

In conclusion, parental thiamine affects the treatment of patients with GAD patients by improving anxiety, decreasing fatigue, and increasing appetite and general well-being.

\section{REFERENCES}

[1] R. C. Kessler, N. Brandenburg, M. Lane, P. Roy-Byrne, P. D. Stang, D. J. Stein and H. U. Wittchen, "Rethinking the Duration Requirement for Generalized Anxiety Disorder: Evidence from the National Comorbidity Survey Replication," Psychological Medicine, Vol. 35, No. 7, 2005, pp. 1073-1082. doi:10.1017/S0033291705004538

[2] R. M. Carter, H. U. Wittchen, H. Pfister and R. C. Kessler, "One-Year Prevalence of Subthreshold and Threshold DSM-IV Generalized Anxiety Disorder in a Nationally Representative Sample," Depression and Anxiety, Vol. 13, No. 2, 2001, pp. 78-88.

[3] M. A. Buist-Bouwman, R. De Graaf, W. A. Vollebergh, J. Alonso, R. Bruffaerts, J. Ormel and ESEMeD/MHEDEA 2000 Investigators, "Functional Disability of Mental Disorders and Comparison with Physical Disorders: A Study among the General Population of Six European Countries," Acta Psychiatrica Scandinavica, Vol. 113, No. 6, 2006, pp. 492-500.

[4] R. C. Kessler, P. E. Greenberg, K. D. Mickelson, L. M. Meneades and P. S. Wang, "The Effects of Chronic Medical Conditions on Work Loss and Work Cutback,"
Journal of Occupational and Environmental Medicine, Vol. 43, No. 3, 2001, 218-225.

[5] C. L. Woodman, R. Noyes Jr., D. W. Black, S. Schlosserand and S. J. Yagla, "A 5-Year Follow-Up Study of Generalized Anxiety Disorder and Panic Disorder," Journal of Nervous \& Mental Disease, Vol. 187, No. 1, 1999, pp. 3-9. doi:10.1097/00005053-199901000-00002

[6] K. A. Yonkers, M. G. Warshaw, A. O. Massion and M. B. Keller, "Phenomenology and Course of Generalised Anxiety Disorder," The British Journal of Psychiatry, Vol. 168, 1996, pp. 308-313. doi:10.1192/bjp.168.3.308

[7] M. D. De Bellis, B. J. Casey, R. E. Dahl, B. Birmaher, D. E. Williamson, K. M. Thomas, D. A. Axelson, K. Frustaci, A. M. Boring, J. Hall and N. D. Ryan, "A Pilot Study of Amygdala Volumes in Pediatric Generalized Anxiety Disorder," Biological Psychiatry, Vol. 48, No. 1, 2000, pp. 51-57. doi:10.1016/S0006-3223(00)00835-0

[8] C. Ferrarese, I. Appollonio, M. Frigo, M. Perego, R. Piolti, M. Trabucchi and L. Frattola, "Decreased Density of Benzodiazepine Receptors in Lymphocytes of Anxious Patients: Reversal after Chronic Diazepam Treatment," Acta Psychiatrica Scandinavica, Vol. 82, No. 2, 1990, pp. 169-173. doi:10.1111/j.1600-0447.1990.tb01376.x

[9] S. Sevy, G. N. Papadimitriou, D. W. Surmont, S. Goldman and J. Mendlewicz, "Noradrenergic Function in Generalized Anxiety Disorder, Major Depressive Disorder, and Healthy Subjects," Biological Psychiatry, Vol. 25, No. 2, 1989, pp. 141-152. doi:10.1016/0006-3223(89)90158-3

[10] M. Germine, A. W. Goddard, S. W. Woods, D. S. Charney and G. R. Heninger, "Anger and Anxiety Responses to $\mathrm{m}$-Chlorophenylpiperazine in Generalized Anxiety Disorder," Biological Psychiatry, Vol. 32, No. 5, 1992, pp. 457-461. doi:10.1016/0006-3223(92)90133-K

[11] K. S. Kendler, M. C. Neale, R. C. Kessler, A. C. Heath and L. J. Eaves, "Generalized Anxiety Disorder in Women. A Population-Based Twin Study," Archives of General Psychiatry, Vol. 49, No. 4, 1992, pp. 267-272.

[12] S. N. Young, "Clinical Nutrition: 3. The Fuzzy Boundary between Nutrition and Psychopharmacology," Canadian Medical Association Journal, Vol. 166, No. 2, 2002, pp. 205-209.

[13] R. J. Wurtman, D. O'Rourke and J. J. Wurtman, "Nutrient Imbalances in Depressive Disorders. Possible Brain Mechanisms," Annals of the New York Academy of Sciences, Vol. 575, 1989, pp. 75-82. doi:10.1111/j.1749-6632.1989.tb53234.x

[14] L. Vognar and J. Stoukides, "Low Plasma Thiamin Levels in Cognitively Impaired Elderly Patients Presenting with Acute Behavioral Disturbances,"Journal of the American Geriatrics Society, Vol. 57, No. 11, 2009, pp. 2166-2168. doi:10.1111/j.1532-5415.2009.02542.x

[15] M. Hamilton, "The Assessment of Anxiety States by Rating," British Journal of Medical Psychology, Vol. 32, No. 1, 1959, pp. 50-55. doi:10.1111/j.2044-8341.1959.tb00467.x

[16] A. Torvik, "Two Types of Brain Lesions in Wernicke's 
Encephalopathy," Neuropathology and Applied Neurobiology, Vol. 11, No. 3, 1985, pp. 179-190. doi:10.1111/j.1365-2990.1985.tb00016.x

[17] K. G. Baker, A. J. Harding, G. M. Halliday, J. J. Kril and C. G. Harper, "Neuronal Loss in Functional Zones of the Cerebellum of Chronic Alcoholics with and without Wernicke's Encephalopathy," Neuroscience, Vol. 91, No. 2, 1999, pp. 429-438.

[18] P. Ruenwongsa and S. Pattanavibag, "Impairment of Acetylcholine Synthesis in Deficient Rats Developed by Prolonged Tea Consumption," Life Sciences, Vol. 34, No. 4, 1984, pp. 365- 370. doi:10.1016/0024-3205(84)90625-8

[19] C. V. Vorhees, D. E. Schmidt and R. J. Barrett, "Effects of Pyrithiamin on Acetylcholine Levels and Utilization in Rat Brain," Brain Research Bulletin, Vol. 3, No. 5, 1978, pp. 493-496. doi:10.1016/0361-9230(78)90078-3

[20] R. G. Mair, C. D. Anderson, P. J. Langlais and W. J. McEntee, "Thiamine Deficiency Depletes Cortical Norepinephrine and Impairs Learning Processes in the Rat," Brain Research, Vol. 360, No. 1-2, 1985, pp. 273-284. doi:10.1016/0006-8993(85)91243-0

[21] K. J. Meador, M. E. Nichols, P. Franke, M. W. Durkin, R. L. Oberzan, E. E. Moore and D. W. Loring, "Evidence for a Central Cholinergic Effect of High-Dose Thiamine," Annals of Neurology, Vol. 34, No. 5, 1993, pp. 724-726. doi:10.1002/ana.410340516

[22] L. L. Barclay, G. E. Gibson and J. P. Blass, "Impairment of Behavior and Acetylcholine Metabolism in Thiamine Deficiency," Journal of Pharmacology and Experimental Therapeutics, Vol. 217, 1981, pp. 537-543.

[23] G. Freund and W. E. Ballinger Jr., "Loss of Muscarinic and Benzodiazepine Neuroreceptors from Hippocampus of Alcohol Abusers," Alcohol, Vol. 6, No. 1, 1989, pp. 23-31.

[24] G. Freund and W.E. Ballinger Jr., "Loss of Muscarinic Cholinergic Receptors from Temporal Cortex of Alcohol Abusers," Metabolic Brain Disease, Vol. 4, No. 2, 1989 , pp. 121-141. doi:10.1007/BF00999390

[25] O. G. Cameron, C. B. Smith, M. A. Lee, P. J. Hollingsworth, E. M. Hill and G. C. Curtis, "Adrenergic Status in Anxiety Disorders: Platelet Alpha 2-Adrenergic Receptor Binding, Blood Pressure, Pulse, and Plasma Catecholamines in Panic and Generalized Anxiety Disorder Patients and in Normal Subjects," Biological Psychiatry, Vol. 28, No. 1, 1990, pp. 3-20. doi:10.1016/0006-3223(90)90427-4

[26] J. L. Abelson, D. Glitz, O. G. Cameron, M. A. Lee, M. Bronzo and G. C. Curtis, "Blunted Growth Hormone Response to Clonidine in Patients with Generalized Anxiety Disorder," Archives of General Psychiatry, Vol. 48, No. 2, 1991, pp. 157-162.

[27] T. Shimizu, H. Hoshino, S. Nishi, S. Nozaki and Y. Watanabe, "Anti-Fatigue Effect of Dicethiamine Hydrochloride Is Likely Associated with Excellent Absorbability and High Transformability in Tissues as a Vitamin B1," European Journal of Pharmacology, Vol. 635, No. 1-3, 2010, pp. 117-123. doi:10.1016/j.ejphar.2010.02.053
[28] O. Van Reeth, "Pharmacologic and Therapeutic Features of Sulbutiamine," Drugs Today (Barc), Vol. 35, No. 3, 1999, pp. 187-192.

[29] O. Kreisler, E. Liebert and M. K. Horwitt, "Psychiatric Observations on Induced Vitamin B Complex Deficiency in Psychotic Patients," American Journal of Psychiatry, Vol. 105, No. 2, 1948, pp. 107-110.

[30] G. D. Mishra, S. A. McNaughton, M. A. O’Connell, C. J. Prynne and D. Kuh, "Intake of B Vitamins in Childhood and Adult Life in Relation to Psychological Distress among Women in a British Birth Cohort," Public Health Nutrition, Vol. 12, No. 2, 2009, pp. 166-174. doi:10.1017/S1368980008002413

[31] Y. D. Bakhai and S. Muqtadir, "Thiamine Deficiency and Psychosis," American Journal of Psychiatry, Vol. 144, No. 5, 1987, pp. 687-688.

[32] I.G. Gontzea, V. Gorcea and F. Popescu, "Biochemichal Assessment of Thiamin Status in Patients with Neurosis," Nutrition and Metabolism, Vol. 19, No. 3-4, 1975, pp. 53157.

[33] D. Benton, J. Fordy and J. Haller, "The Impact of Long-Term Vitamin Supplementation on Cognitive Functioning," Psychopharmacology, Vol. 117, No. 3, 1995, pp. 298-305.

[34] J. Brozek and W. O. Caster, "Psychologic Effects of Thiamine Restriction and Deprivation in Normal Young Men," American Journal of Clinical Nutrition, Vol. 5, No. 2, 1957, pp. 109-120.

[35] L. J. Smidt, F. M. Cremin, L. E. Grivetti and A. J. Clifford, "Influence of Thiamin Supplementation on the Health and General Well-Being of an Elderly Irish Population with Marginal Thiamin Deficiency," Journal of Gerontology, Vol. 46, No. 1, 1991, pp. M16-M22.

[36] H. Heseker, W. Kuebler, J. Westenhoefer and V. Pudel, "Psychische Veräderungen als Frühzeichen Einer Suboptitalen Vitaminversorgung," Ernährungsumschau, Vol. 37, 1990, pp. 87-94.

[37] I. R. Bell, J. S. Edman, F. D. Morrow, D. W. Marby, G. Perrone, H. L. Kayne, M. Greenwald and J. O. Cole, "Vitamin B1, B2, and B6 Augmentation of Tricyclic Antidepressant Treatment in Geriatric Depression with Cognitive Dysfunction," American Journal of Clinical Nutrition, Vol. 11, No. 2, 1992, pp. 159-163.

[38] D. Lonsdale and R. J. Shamberger, "Red Cell Transketolase as an Indicator of Nutritional Deficiency," American Journal of Clinical Nutrition, Vol. 33, No. 2, 1980, pp. 205-211.

[39] T. J. Wilkinson, H. C. Hanger, J. Elmslie, P. M. George and R. Sainsbury, "The Response to Treatment of Subclinical Thiamine Deficiency in the Elderly," American Journal of Clinical Nutrition, Vol. 66, No. 4, 1997, pp. 925-928.

[40] D. Benton, R. Griffiths and J. Haller, "Thiamine Supplementation Mood and Cognitive Functioning," Psychopharmacology (Berl), Vol. 129, No. 1, 1997, pp. 66-71.

[41] R. A. Baum and F. L. Iber, "Thiamin-The Interaction of Aging, Alcoholism, and Malabsorption in Various Popu- 
lations," World Review of Nutrition \& Dietetics, Vol. 44, 1984, pp. 85-116.

[42] K. Schaller and H. Holler, "Thiamine Absorption in Rat. II. Intestinal Alkaline Phosphatase Activity and Thiamine Absorption from Rat Small Intestines in-Vitro and inVivo," International Journal for Vitamin and Nutrition Research, Vol. 45, No. 1, 1975, pp. 30-38.

[43] G. Rindi, V. Ricci, G. Gastaldi and C. Patrini, "Intestinal Alkaline Phosphatase Can Transphosphorylate during Intestinal Transport in the Rats," Archives of Physiology and Biochemistry, Vol. 103, No. 1, 1995, pp. 33-38. doi:10.3109/13813459509007560

[44] K. V. Q. Luong and L. T. H. Nguyen, "Adult Hypophosphatasia and a Low Level of Red Blood Cell Thiamine Pyrophosphate," Annals of Nutrition and Metabolism, Vol. 49, No. 2, 2005, pp. 107-109. doi:10.1159/000084743

[45] P. Höhn, H. Gabbert and R. Wagner, "Differentiation and Aging of the Rat Intestinal Mucosa. II. Morphological, Enzyme Histochemical and Disc Electrophoretic Aspects of the Aging of the Small Intestinal Mucosa," Mechanisms of Ageing and Development, Vol. 7, 1978, pp. 217226. doi:10.1016/0047-6374(78)90068-4
[46] I. Jang, K. Jung and J. Cho, "Influence of Age on DuoDenal Brush Border Membrane and Specific Activities of Brush Border Membrane Enzymes in Wistar Rats," Experimental Animals, Vol. 49, No. 4, 2000, pp. 281-287.

[47] T. E. Friedman, T. C. Kmieckiak, P. K. Keegan and B. B. Sheft, "The Absorption, Destruction, and Excreyion of Orally Administered Thiamine by Human Subjects," Gastroenterology, Vol. 11, 1948, pp. 100-114.

[48] A. B. Morrison and J. A. Campbell, "Vitamin Absorption Studies. I. Factors Influencing the Excretion of Oral Test Doses of Thiamine and Riboflavin by Human Subjects," Journal of Nutrition, Vol. 72, 1960, pp. 435-440.

[49] H. Baker, O. Frank and S. P. Jaslow, "Oral versus Intramuscular Vitamin Supplement for Hypovitaminosis in the Elderly," Journal of the American Geriatrics Society, Vol. 28, No. 1, 1980, pp. 42-45.

[50] T. Sasaki, T. Yukizane, H. Atsuta, H. Ishikawa, T. Yoshiike, T. Takeuchi, K. Oshima, N. Yamamoto, A. Kurumaji and T. Nishikawa, "A Case of Thiamine Deficiency with Psychotic Symptoms-Blood Concentration of Thiamine and Response to Therapy," in Japanese, Seishin Shinkeigaku Zasshi, Vol. 112, No. 2, 2010, pp. 97-110. 